\title{
The Effect of Plasticizers on Mechanical Properties and Water Vapor Permeability of Gelatin-Based Edible Films Containing Clay Nanoparticles
}

\author{
Mahsa Rezaei ${ }^{1}$, Ali Motamedzadegan ${ }^{1,2 *}$ \\ ${ }^{1}$ Faculty of Food Industries, Ayatollah Amoli Branch, Islamic Azad University, Amol, Iran \\ ${ }^{2}$ Department of Food Science, Sari University of Agricultural Sciences and Natural Resources, Sari, Iran \\ Email: "mmohse@yahoo.com
}

Received 16 October 2015; accepted 21 December 2015; published 24 December 2015

Copyright (C) 2015 by authors and Scientific Research Publishing Inc.

This work is licensed under the Creative Commons Attribution International License (CC BY). http://creativecommons.org/licenses/by/4.0/

(c) (i) Open Access

\section{Abstract}

The effects of glycerol and sorbitol as two plasticizers on mechanical properties, water vapor permeability, thermal properties, color and capability of heat sealing of gelatin films (of phytophagous fish, bovine gelatin with high gel-forming ability, and bovine gelatin with low gel-forming ability) containing clay nanoparticles were studied in this research. For this purpose, $6 \times 2 \times 3$ factorial experiments using the completely randomized design and comparison of the means at $95 \%$ confidence level $(\alpha=0.05)$ were performed. Higher concentrations of plasticizers increased percentage elongation to the breaking point. When glycerol concentration was raised to over $20 \%$, flexibility of the layers improved but their water vapor permeability increased. The minimum passage of water vapor was that of fish-skin gelatin films containing clay nanoparticles and $\mathbf{3 0 \%}$ sorbitol, and the maximum that of bovine gelatin films with high gel-forming ability which contained nanoparticles but no plasticizers $(p<0.05)$. There were no significant differences with respect to color in the various treatments $(p>0.05)$. All samples had heat sealing capability, and fish-skin gelatin films containing clay nanoparticles had better heat sealing capability compared with the other samples so that fish-skin gelatin films containing clay nanoparticles with $25 \%$ glycerol and 5\% sorbitol had the highest flexibility and tensile strength, and remained attached to where they were heat sealed. Electron microscope images showed that films without plasticizers had uniform surfaces, but that samples containing glycerol at concentrations of over $0.20 \mathrm{~g} / \mathrm{g}$ gelatin exhibited cavities between gelatin chains and that water vapor permeability in gelatin films containing clay nanoparticles.

${ }^{*}$ Corresponding author.

How to cite this paper: Rezaei, M. and Motamedzadegan, A. (2015) The Effect of Plasticizers on Mechanical Properties and Water Vapor Permeability of Gelatin-Based Edible Films Containing Clay Nanoparticles. World Journal of Nano Science and Engineering, 5, 178-193. http://dx.doi.org/10.4236/wjnse.2015.54019 


\section{Keywords}

\section{Gelatin, Clay Nanoparticles, Plasticizer, Mechanical Properties, Water Vapor Permeability}

\section{Introduction}

More than five billion tons of waste from packaging materials is produced annually in the world, $30 \%$ of which are plastic compounds. Pollution with synthesized plastics, which is called white pollution, forms a major part of environmental pollution in industrial countries, and also in developing countries like Iran that have weak plastic recovery systems. Concern for environmental pollution caused by synthesized plastics has attracted researchers to studying the possibility of using natural biodegradable polymers in the production of packaging materials [1]. Use of edible coatings and films for increasing the shelf life of food materials has been common from very old times. For example, covering fresh oranges and lemons with wax to delay the drying out of their peels was tested in the $12^{\text {th }}$ and $13^{\text {th }}$ centuries in China. These coatings substantially reduce evaporation of water from food materials and prevent exchange of respiratory gases and, thereby, decrease fermentation. Natural polymers are biodegradable in nature and are converted into natural products such as $\mathrm{CO}_{2}$, water, ethane, and biomass during a composting process [2] [3].

Manufacture of earthen vessels was a considerable progress in food storage. About 4000 years ago, inhabitants of present day Pakistan used earthen vessels to store food. In $530 \mathrm{AD}$, Iranians made use of earthen vessels with lids to send water and food materials to conquered lands in Egypt, and reused the emptied vessels. In brief, making vessels for preserving and storing food materials was of interest from the Equator to the Poles and people tried to perfect these vessels. Considering what was said above, although the art of packaging food materials was as old as human history, most researchers believed that the packaging industry was founded in 1840 when the Frenchman Operetta developed the art of preserving food materials in glass containers with lids. Since then, we have been witnessing the ever-increasing flourishing of this industry [4].

Although, initially, the purpose of food packaging is to store seasonal products and facilitate the transfer of food materials from one place to another, nowadays the advertising on food packages has given food packaging a wider meaning. Based on sources related to this field of science and technology, packaging can be defined as follows:

1. Packaging is a system that reduces the required time to prepare merchandise for transportation, storage, and retail sale;

2. Packaging is a concept that ensures reliable delivery of merchandise in good condition and with minimum cost to the end consumer;

3. Packaging is an economic-technical operation that minimizes delivery costs while increasing sales and, hence, improves profitability.

Preparation and production of packaging materials with the goal of preserving and improving quality, increasing shelf life, and protecting food materials against various microbial infections and chemical decays have been one of the concerns and research subject of researchers active in the food industry in recent years. Production of plastic packaging materials such as polyolefins, polyesters, polyamides, etc. has expanded in recent years due to the abundance and low price of the raw materials required for their production. On the other hand, the increase in environmental pollution and the non-biodegradability of such materials has attracted the interest of many researchers in producing biodegradable packaging materials that have the capability to preserve food materials. That is why many attempts have been made to produce packaging materials of natural origin (proteins, fats, and carbohydrates) in the form of films or coatings, the various types of which will be described in the following sections. The type and concentration of plasticizers influence film properties through affecting the interactions between protein molecules. Plasticizers are added to decrease the rigidity and increase the flexibility of films. In the case of certain proteins, some plasticizers help us to obtain desirable mechanical properties while only slightly affecting their inhibitory features.

Many studies have been carried out on the technology of biodegradable and edible films and coatings, but the effects of plasticizers on gelatin films containing clay nanoparticles have not been thoroughly studied yet. This research intended to study the capability of edible films that are based on gelatin, contained clay nanoparticles, and to which glycerol and sorbitol are added as plasticizers. 


\section{Materials and Methods}

\subsection{Extraction of Fish Gelatin}

Commercial gelatin type 1 (bovine gelatin with high gel forming ability and of 390 Bloom grams), commercial gelatin type 2 (bovine gelatin with low gel forming ability and of 170 Bloom grams), and glycerol and sorbitol were bought from Merck Company.

\subsection{Preparing Nanocomposite Plasticizer/Fish Gelatin/Clay Nanoparticle Films}

Nanocomposite films were made using the solution casting method [5]. The Nanoclay solution was prepared by mixing clay nanoparticles ( $5 \%$ gelatin by weight/FPH) with $50 \mathrm{ml}$ of water stirred at room temperature for 24 hours, followed by complete homogenization of the solution for 10 minutes using ultrasonic devices. The gelatin/plasticizer solution for making the films was prepared at optimal concentration using the method described below.

The solvent evaporation method was used to prepare the films. During the first stage of the experiment, 3 grams of gelatin were mixed in $100 \mathrm{ml}$ of water containing clay nanoparticles [6] together with a $0,10,15,20$, $25 \%$, and $30 \%$ by weight combination of gelatin, sorbitol, and glycerol as shown in Table 1 . This table shows treatments used in this research based on type of gelatin containing clay nanoparticles. The mixture was then poured into $8.4 \mathrm{~cm}$ long and $4.8 \mathrm{~cm}$ wide perforated plexi containers and dried in an oven for 24 hours. After drying, the films were removed from the containers and stored at $25^{\circ} \mathrm{C}$ and $50 \% \mathrm{RH}$ in a desiccator containing saturated magnesium nitrate solution until testing time [7].

\subsection{Measuring Film Thickness}

A micrometer with an accuracy of $0.01 \mathrm{~mm}$ was used to measure film thickness, and the mean thickness of at least 10 randomly selected spots on the film was reported [7].

\subsection{Mechanical Properties}

Following the D882ASTM standard and using a Santam STM-5 texture analyzer at the Laboratory of Material Analysis of the Food Sciences and Technology Department at Sari Agricultural Sciences and Natural Resources University, the three parameters of tensile strength, elongation to the breaking point, and Young's modulus were calculated. The samples were conditioned at $25^{\circ} \mathrm{C}$ and $\mathrm{RH}$ of $50 \% \pm 3 \%$ in a desiccator containing a saturated solution of magnesium nitrate for at least two days. The films were cut in the form of rectangular bands $4 \mathrm{~cm}$ long and $1 \mathrm{~cm}$ wide, and installed between the two jaws of the device at a specific initial distance. The jaws moved away from each other at the rate of $10 \mathrm{~mm} / \mathrm{min}$ until the film was torn. Young's modulus, stress, and strain were measured at the breaking point. The films were tested immediately after they were removed from the desiccator [7].

\subsection{Water Vapor Permeability}

Water vapor flow rate was calculated according to the ASTM E96 standard. The films were sealed to cup mouths with paraffin and fixed by o-rings that were placed around them. The cups, which had a uniform depth

\begin{tabular}{|c|c|c|c|c|c|c|c|c|}
\hline \multirow{2}{*}{ Type of gelatin containing clay nanoparticles } & \multicolumn{8}{|c|}{$\begin{array}{l}\text { Percentage glycerol by weight: percentage sorbitol to } \\
\text { gelatin by weight (gram per gram of gelatin) }\end{array}$} \\
\hline & A & B & $\mathrm{C}$ & $\mathrm{D}$ & $\mathrm{E}$ & $\mathrm{F}$ & G & $\mathrm{H}$ \\
\hline Bovine gelatin with high Bloom values & $0: 0$ & $30: 0$ & $25: 5$ & $20: 10$ & $15: 10$ & $10: 10$ & $5: 10$ & $0: 10$ \\
\hline Bovine gelatin with low Bloom values & $0: 0$ & $30: 0$ & $25: 0$ & $20: 0$ & $15: 0$ & $10: 0$ & $5: 0$ & $0: 0$ \\
\hline Fish skin & $0: 0$ & $30: 0$ & $25: 0$ & $20: 0$ & $15: 0$ & $10: 0$ & $5: 0$ & $0: 0$ \\
\hline
\end{tabular}


and internal diameter of $17.9 \mathrm{~mm}$ and were filled with a saturated solution of magnesium nitrate, were put in a desiccator with $\mathrm{RH}$ of $50 \% \pm 3 \%$. The whole apparatus was kept at $25^{\circ} \mathrm{C}$. The relative humidity gradient on the two sides of the films was 50:0. The cups were weighed at specified intervals using a balance with an accuracy of 0.0001 gram. Water vapor flow rate was calculated using the following relation [7]:

$$
W V P=W V T R_{X} \times[P 0(R H 1-R H 2)] .
$$

In the above relation, $\mathrm{x}$ is the mean film thickness, $\mathrm{P}_{\mathrm{o}}(\mathrm{kPa})$ the net water vapor pressure (which is 3.159 at $\left.25^{\circ} \mathrm{C}\right)$, (RH1-RH2) the relative humidity gradient employed in the test, and WVTR $\left(\mathrm{g} / \mathrm{h} \cdot \mathrm{m}^{2}\right)$ the water vapor flow rate.

\subsection{Color and Turbidity}

The image processing method was used to measure color and turbidity. Digital photos must first be taken to evaluate the $\mathrm{L}^{*}, \mathrm{a}^{*}$, and $\mathrm{b}^{*}$ parameters using software. To do this, a $50 \times 50 \times 60 \mathrm{~cm}$ box (length, width, and height, respectively) was made and its inner walls were painted white for the lamp light to be reflected from all directions onto the sample. A 60W LED light bulb ( $\mathrm{T}>5000 \mathrm{~K}$, Cixin) was used to provide light, and a digital camera to take photos of the samples. The camera was placed at a distance of $25 \mathrm{~cm}$ from the sample and its resolution was set to $1600 \times 1200$ pixels. The self-timer was set to a 10 -second delay so that the box door could be closed when photos were taken. The digital photos were transferred to a computer and analyzed using Photoshop 8. To do this, a circle with the diameter of 100 pixels was selected, the Average Filter Blur option was used to calculate the average colors of the pixels in the selected section, and the Information window was utilized to extract the values of $\mathrm{L}^{*}, \mathrm{a}^{*}$, and $\mathrm{b}^{*}$. The extent of deviation of the color of the samples was calculated using the following relation:

$$
\begin{gathered}
\text { Whiteness }=100-\left[\left(100-L^{*}\right)^{2}+a^{* 2} b^{* 2}\right]^{1 / 2} \\
\Delta E=\left[\left(\Delta L^{* 2}\right)+\left(\Delta a^{* 2}\right)+\left(\Delta b^{* 2}\right)\right]^{1 / 2} .
\end{gathered}
$$

\subsection{Glass Transition Temperature Test ( $\left.\mathrm{T}_{\mathrm{g}}\right)$}

The method introduced by Rivero et al. for differential scanning calorimetry analysis was used, with some modifications, to measure the glass transition temperature. The equipment used in differential scanning calorimetry analysis measures energy that is exchanged in the form of heat (at constant pressure) in a physical or chemical process. The samples weighing $6-7 \mathrm{mg}$ were completely fixed on a pan (of stainless steel or aluminum) and an empty pan was used as reference. The samples were analyzed in the temperature range of $50^{\circ} \mathrm{C}-200^{\circ} \mathrm{C}$, and the rate of temperature increase was $10^{\circ} \mathrm{C} / \mathrm{min}[8]$.

$\mathrm{T}_{\mathrm{m}}$ : melting temperature $\left({ }^{\circ} \mathrm{C}\right)$.

$\Delta \mathrm{H}$ : enthalpy $(\mathrm{j} / \mathrm{g}$ dry basis).

$\mathrm{T}_{\mathrm{g}}$ : glass transition temperature $\left({ }^{\circ} \mathrm{C}\right)$.

\subsection{Film Structure}

A scanning electron microscope was used to determine film structure at the Nanoelectronics Laboratory in the School of Electrical and Computer Engineering of Tehran University. Sections with specified dimensions were taken from each sample, fixed on special pins, and placed in the gold deposition instrument. The completely gold-covered sections were then transferred into the SEM and images were taken at 10,000×, 30,000×, and $60,000 \times$ magnifications.

\subsection{Heat Sealing}

The prepared films, that were stored in a desiccator containing a saturated magnesium nitrate solution at $\mathrm{RH}$ of $50^{\circ} \mathrm{C} \pm 3^{\circ} \mathrm{C}$, were taken out and each two thin film layers from every treatment were placed on top of each on a distance of two centimeters. They were sealed together by a heat-sealing machine at the same time and temperature, and were then exposed to tensile force applied by a Santam STM-5 texture analyzer to measure the 
strength of the heat sealing, and the elongation to the breaking point, the tensile strength of the spot where the films were heat sealed together.

\subsection{Solubility in Water}

The water solubility of the edible films was determined using the Gontard et al. method [9]. The films were cut and weighed. Percentage water solubility was the percentage of the dry matter of the films that dissolved after they were immersed in water for 24 hours. The percentage of the original raw material in each film was determined after the film was kept at $100^{\circ} \mathrm{C}$ for 24 hours. The films that were cut into 2 by 2 centimeter pieces were immersed in $50 \mathrm{ml}$ of water that contained a small amount of sodium azide $(0.02 \% \mathrm{w} / \mathrm{v})$ to prevent growth of microorganisms. They were stirred intermittently for 24 hours at $20^{\circ} \mathrm{C}$, and the films that did not dissolve were removed and dried as much as possible (at $100^{\circ} \mathrm{C}$ for 24 hours) to determine the weight of the dry matter.

Percentage solubility was calculated using relation 4:

$$
\text { Percentage solubility }=\left(M_{d}-M_{s}\right) / M_{d} \times 100 .
$$

In the above relation, $M_{d}$ was the original dry weight of the film and $M_{s}$ the dry matter weight of the undissolved film.

\subsection{Microbial Test}

The antimicrobial activity of the films was measured using the agar diffusion method. Food pathogens such as E. coli and $L$. monocytogenes were used as test organisms. They were cultured under sterile conditions on TSB and BHI Broth culture media at $37^{\circ} \mathrm{C}$ for 16 hours. The old liquid culture media $(0.1 \mathrm{ml})$ of each bacterial species was transferred (under sterile conditions) to Eppendorfs containing $0.9 \mathrm{ml}$ of sterile water and diluted to twice their original volumes. One $\mathrm{ml}$ of the diluted liquid medium was added to the TSB and BHI (100 ml) agar media before plating and a drill for making wells in agar was used to make wells with the diameter of $4.5 \mathrm{~mm}$. The sample liquids $(80 \mu \mathrm{l})$ were added to the wells and put in an incubator at $37^{\circ} \mathrm{C}$ for 24 hours. The inhibitory region was determined by measuring the diameter of the zone of inhibition around the wells [5].

\subsection{Antioxidant Activity}

The method introduced by Benzie and Strain [10] was used to measure the reduction potential of iron ions in the samples. This method is based on increased absorption at $595 \mathrm{~nm}$ due to the formation of the tripyridyl triazine complex (TPTZ) Fe ( $\Pi$ in the presence of reducing agents at $37^{\circ} \mathrm{C}$. Gelatin and FPH dissolved in distilled water, while film samples dissolved in $0.5 \mathrm{M}$ acetic acid. Absorption was read after 30 minutes on a spectrophotometer, and the standard $\mathrm{FeSO}_{4.7} \mathrm{H}_{2} \mathrm{O}$ curve was obtained, which relates $\mathrm{FeSO}_{4.7} \mathrm{H}_{2} \mathrm{O}$ concentration to absorption at 595 $\mathrm{nm}$. Results were expressed in $\mu \mathrm{M}$ of FeSO4.7H20 equivalent per gram of the sample.

\section{Results and Discussion}

\subsection{Mechanical Properties}

Figure 1 shows the mechanical behavior of gelatin films containing clay nanoparticles without plasticizers. The films exhibited high tensile strength and low percentages of elongation to the breaking point, which indicated their brittle property. Cao et al. [7] reported similar behavior in bovine gelatin films with high or low Bloom values containing clay nanoparticles. All three types of gelatin films containing clay nanoparticles behaved similarly, but Bovine gelatin films with high Bloom values containing clay nanoparticles had greater tensile strength and required higher tensile force. Bovine gelatin films with low Bloom values containing clay nanoparticles and fish-skin gelatin films containing clay nanoparticles exhibited identical behaviors while, at identical stress, fish-skin gelatin films containing clay nanoparticles had higher elongation to the breaking point compared to bovine gelatin films with low Bloom values that contained clay nanoparticles.

Figure 2 indicates the mechanical behavior of fish-skin gelatin films containing clay nanoparticles and 25\% glycerol and sorbitol by weight. Gelatin films containing clay nanoparticles and sorbitol had greater tensile strength compared to those that had glycerol instead of sorbitol, which could be due to increased fluidity of lateral branches and because of matrix lubrication when glycerol was added to these films. It seems glycerol wea- 


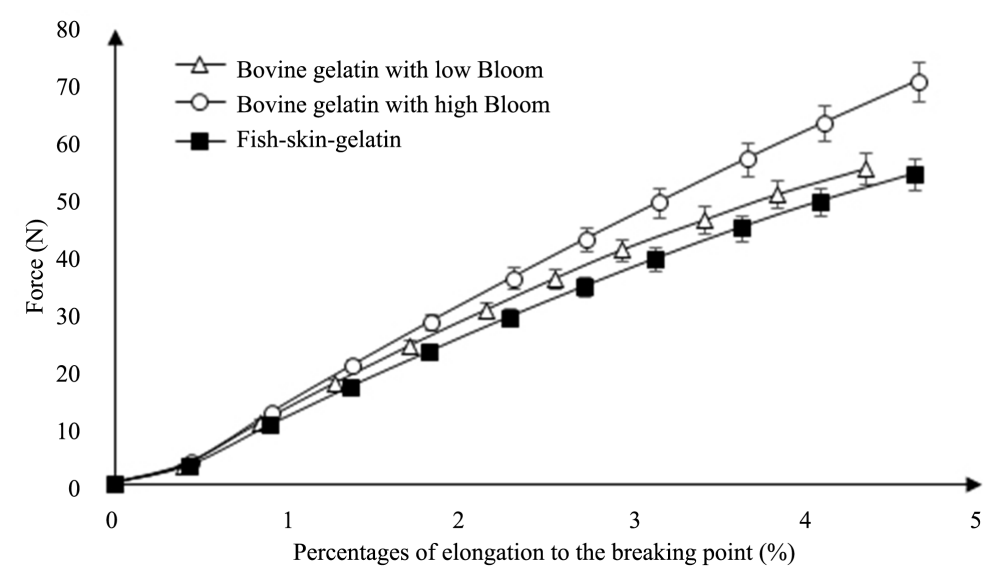

Figure 1. Mechanical behavior of gelatin films containing clay nanoparticles without plasticizer.

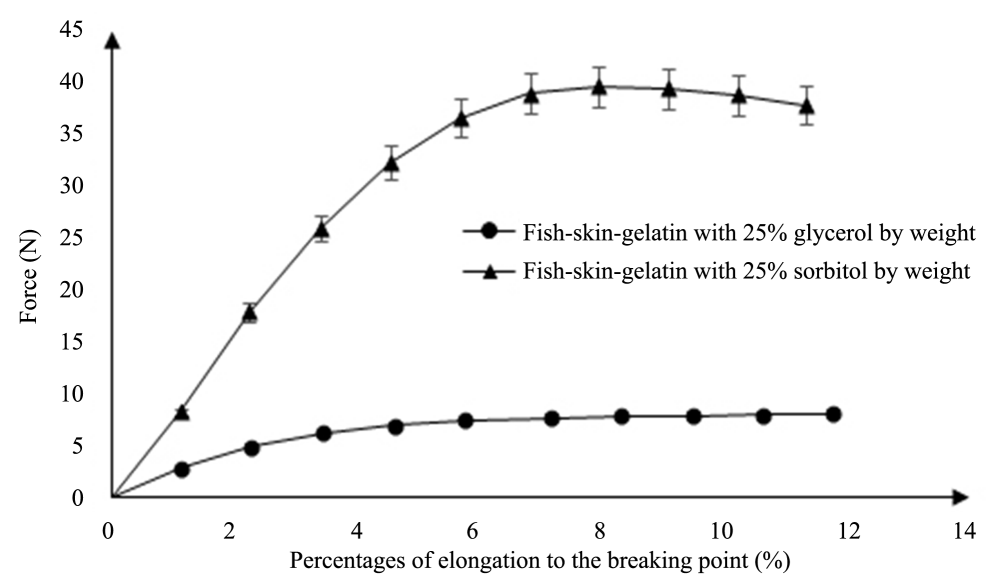

Figure 2. Mechanical behavior of fish-skin gelatin containing clay nanoparticles with $25 \%$ glycerol and sorbitol by weight.

kens film structure leading to reductions in tensile strength and to substantial increases in the percentage elongation to the breaking point.

Figure 3 and Figure 4 show the effects of glycerol and sorbitol on mechanical behavior such as tensile strength, percentage elongation to the breaking point, and Young's modulus in gelatin films containing clay nanoparticles. Increases in the concentration of the plasticizers improved percentage elongation to the breaking point except when glycerol percentage by weight was raised from $25 \%$ to $30 \%$ in fish-skin gelatin films that contained clay nanoparticles, which could be due to increased fluidity in film structure. It appears glycerol at the concentration of $25 \%$ by weight greatly weakened gelatin structure, which led to reductions in tensile strength and Young's modulus in all of the samples. It seems glycerol increased percentage elongation to the breaking point and reduced tensile strength and Young's modulus in films treated by it through weakening gelatin structure by weakening the bonds through coming in between the lateral branches. After a few days, reductions were observed in film flexibility, probably because the plasticizers had moved to the surface of the films, following which the films had hardened. Young's modulus is the ratio of stress to strain in the linear portion of the curve, and can be obtained by measuring the slope of the stress-strain curve in its linear portion. Young's modulus is the required force to break the bonds in the samples, and it is related to the strength of the related material

Adding sorbitol to bovine gelatin films with high or low Bloom value and containing clay nanoparticles reduced tensile strength and Young's modulus. In films made from bovine gelatin with high Bloom values that contained clay nanoparticles, considerable reductions in tensile strength were observed when sorbitol was added at the concentration of $10 \%$ by weight, but no significant changes in tensile strength were detected when its 

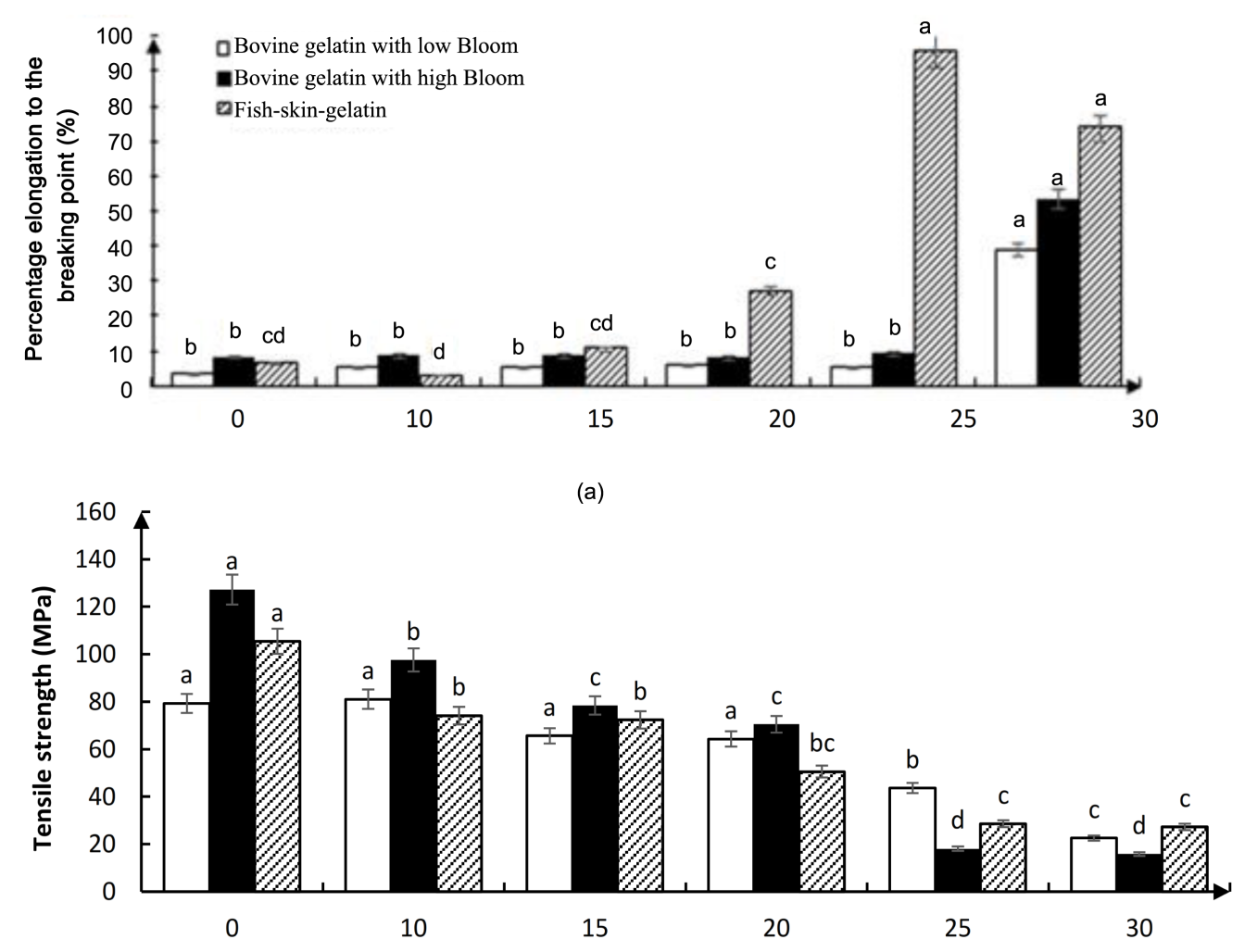

(b)

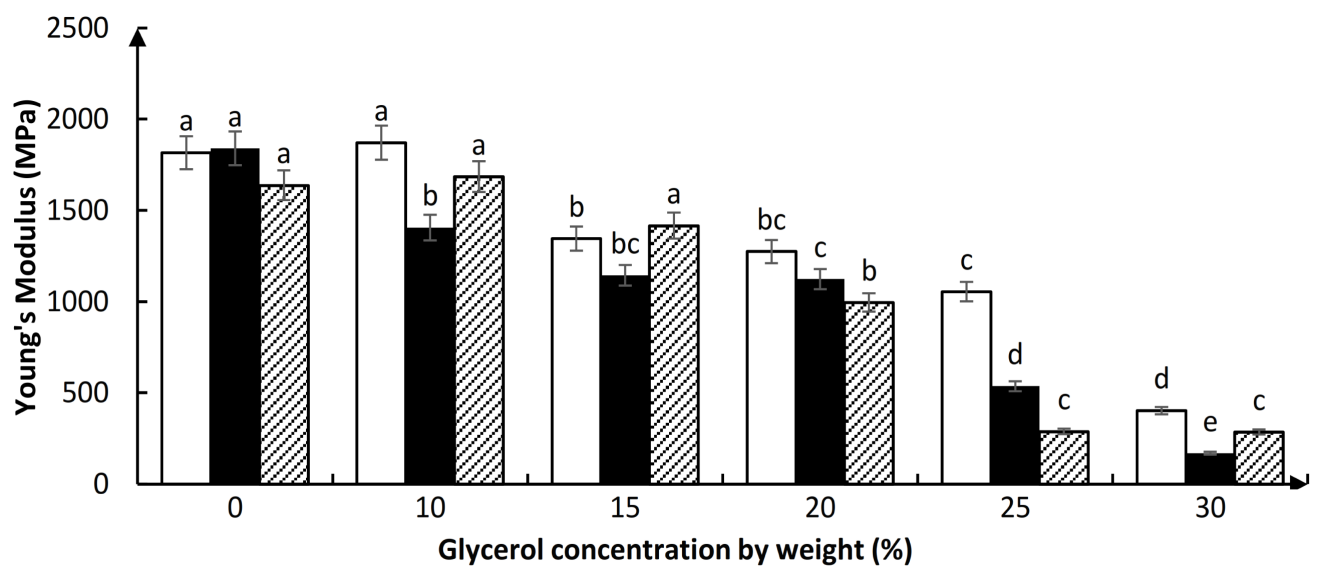

(c)

Figure 3. Results related to the effects of glycerol on (a) percentage elongation to the breaking point; (b) tensile strength; (c) Young's modulus in the three types of gelatin films containing clay nanoparticles. Different letters suggest averages of the studied property in each of the tests were significantly different $(p<0.05)$.

concentration was raised from $10 \%$ up to $30 \%$ by weight. Moreover, no significant changes were noticed in Young's modulus in these samples when sorbitol concentration increased from $10 \%$ up to $25 \%$ by weight. When sorbitol concentration was raised from $25 \%$ to $30 \%$ by weight, young's modulus improved. It seems glycerol was a better plasticizer than sorbitol with respect to mechanical properties because it increased percentage elongation to the breaking point besides imparting suitable tensile strength to the films. Films with high ultimate tensile strength and low percentage increase to the breaking point are brittle, and those with low ultimate tensile strength and high percentage elongation to the breaking point are weak.

Figure 5 presents the combined effects of sorbitol and glycerol on mechanical properties of gelatin films with 

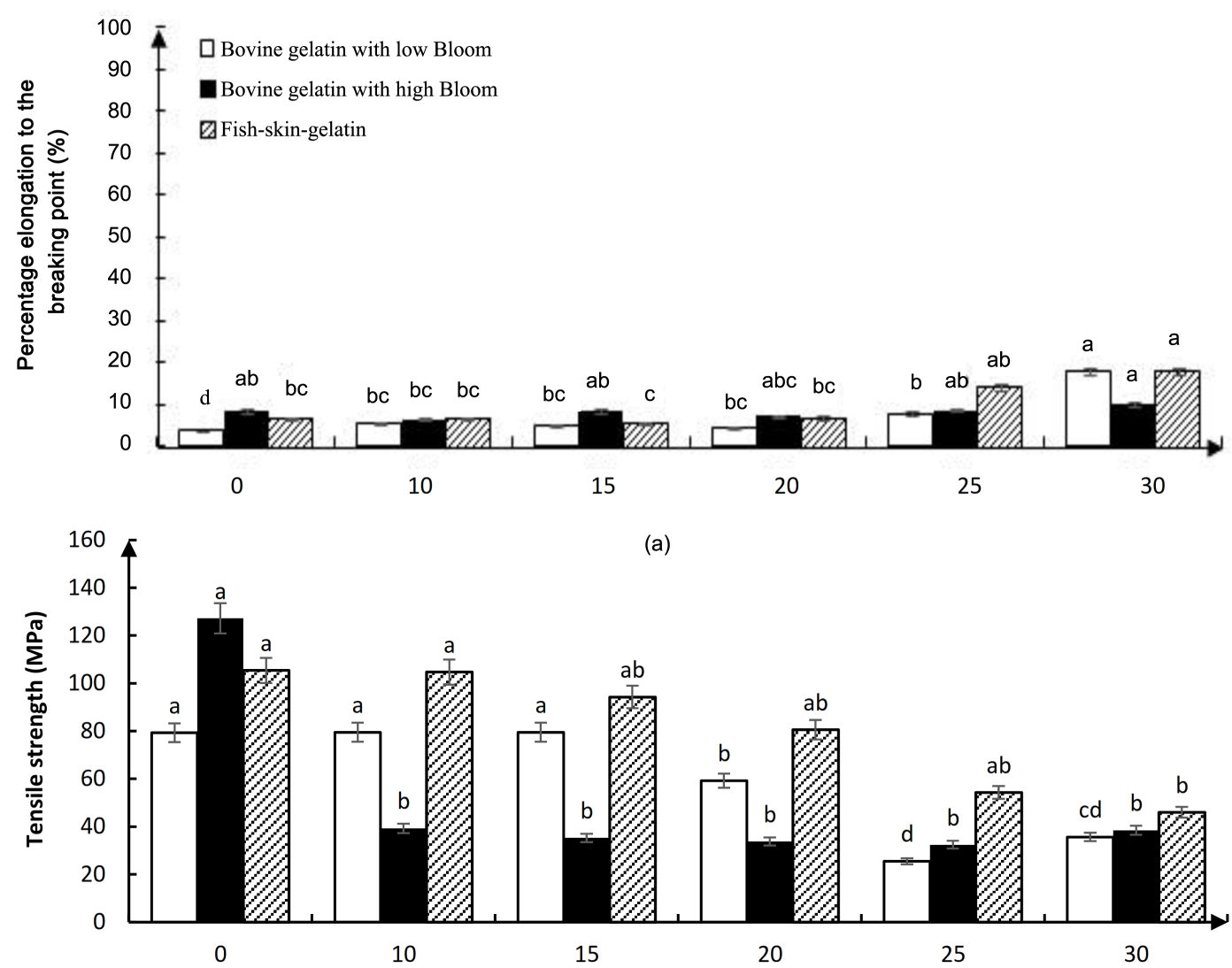

(a)

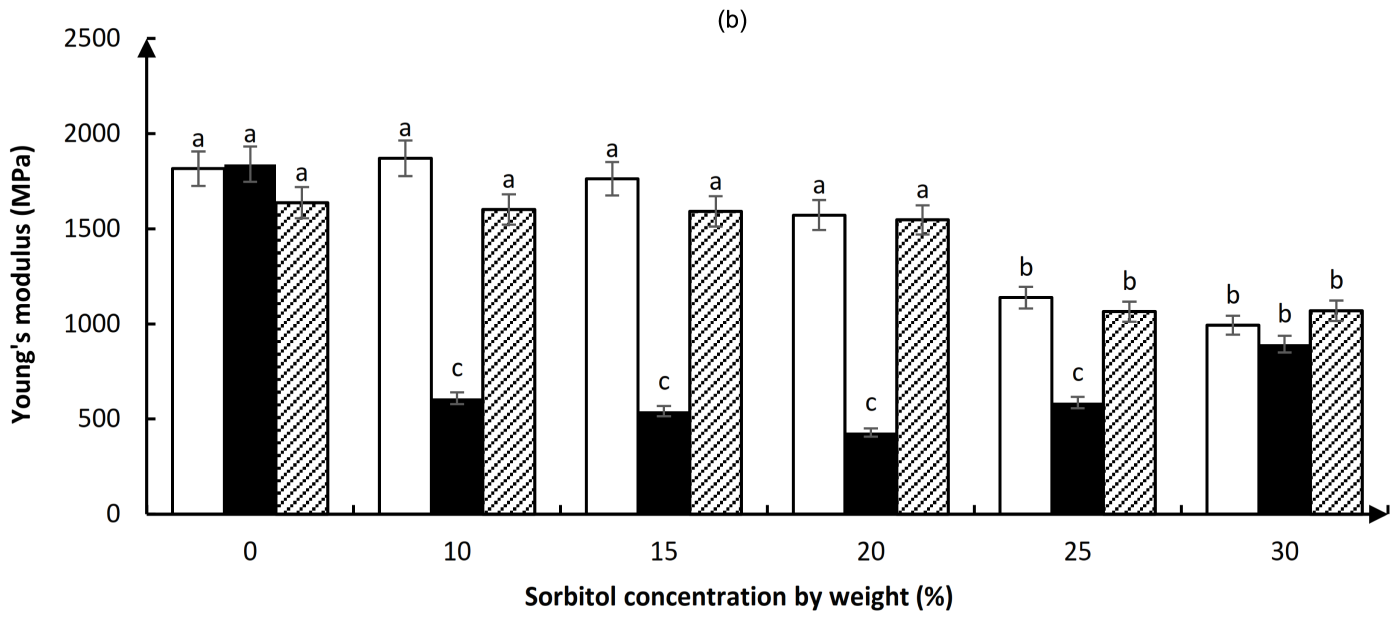

(c)

Figure 4. Results related to the effects of sorbitol on (a) percentage elongation to the breaking point (b) tensile strength, and (c) Young's modulus in the three types of gelatin films containing clay nanoparticles. Different letters in each section suggest the averages of the studied property in each of the tests were significantly different $(\mathrm{p}<0.05)$.

clay nanoparticles. In all three types of the studied gelatin films, films without plasticizers had the maximum tensile strength and Young's modulus $(\mathrm{p}<0.05)$. With increases in plasticizer concentration, tensile strength and Young's modulus declined and percentage elongation to the breaking point improved. In bovine gelatin films with high or low Bloom values that contained clay nanoparticles, tensile strength and Young's modulus increased when plasticizers were added at concentrations higher than $0.20 \mathrm{~g}$ sorbitol/g gelatin $(\mathrm{p}<0.05)$. This could be due to water repellency in films containing sorbitol. These results conform to those found by Ghasem- 


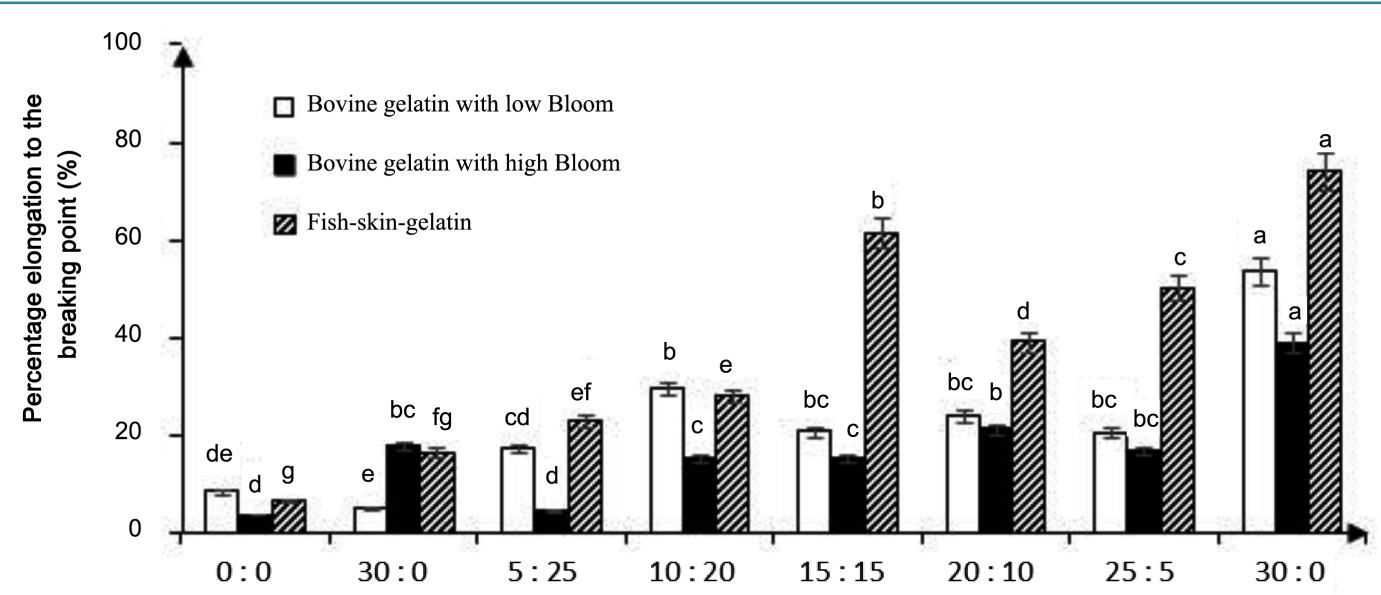

(a)

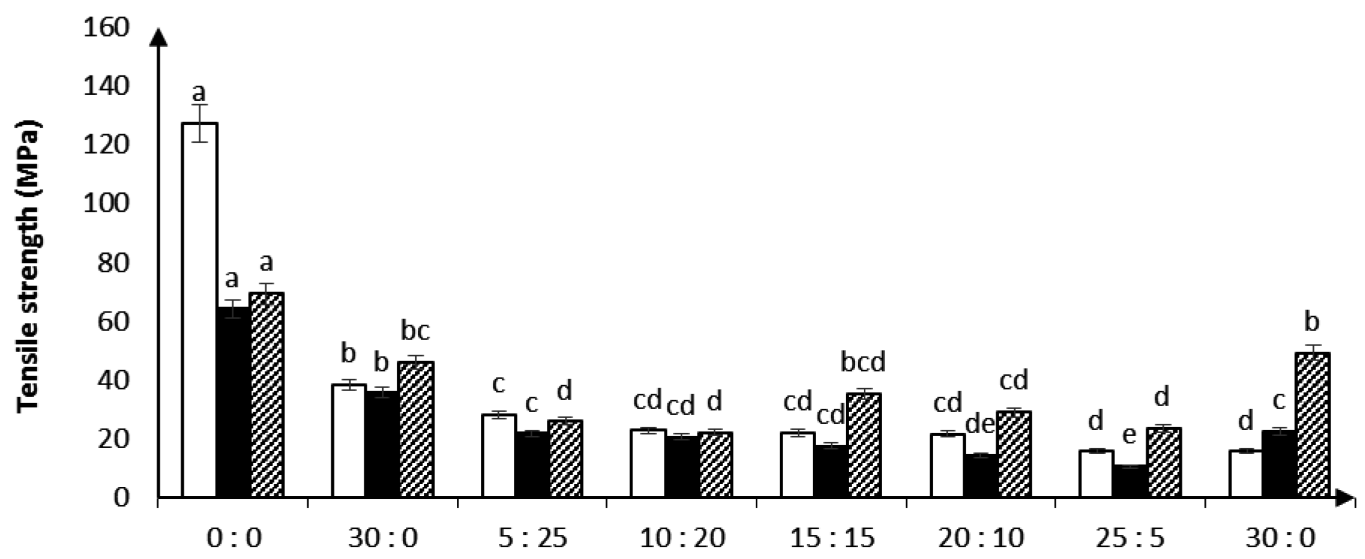

(b)

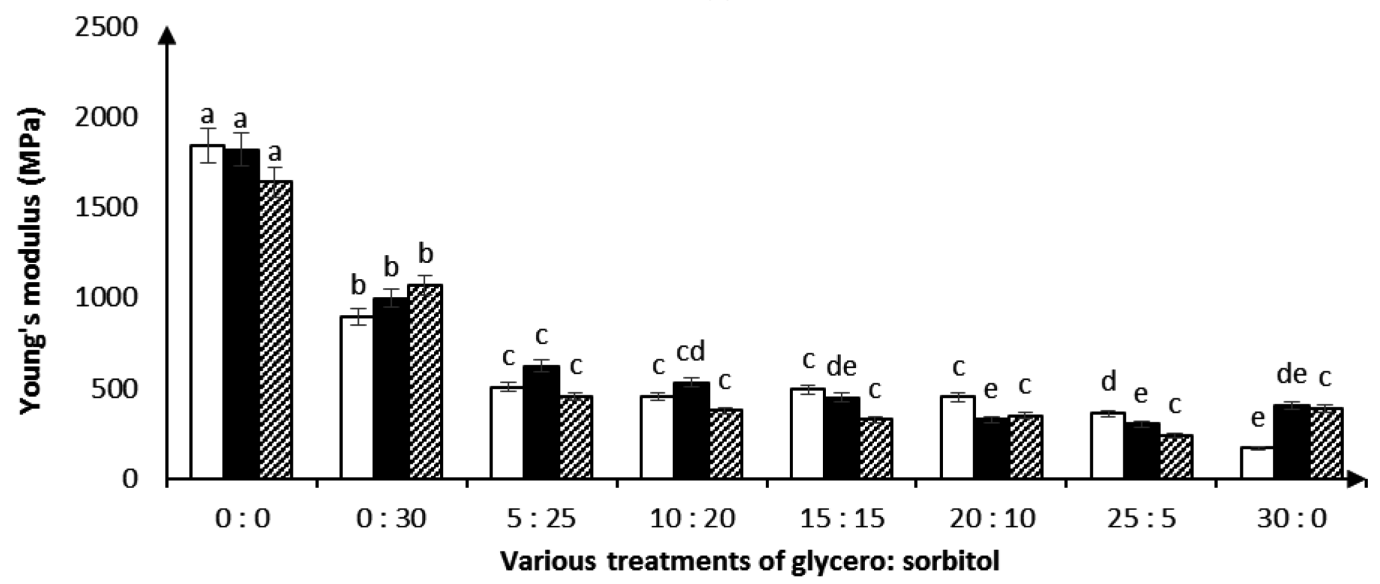

(c)

Figure 5. Results related to the various treatments of glycerol: sorbitol on (a) percentage elongation to the breaking point; (b) tensile strength; and (c) Young's modulus in three types of gelatin films containing clay nanoparticles. Different letters in each section suggest the averages of the studied property in each of the tests were significantly different $(\mathrm{p}<0.05)$.

loo et al. [11] and by Oses et al. [12]. Films with higher concentrations of sorbitol were less flexible and had greater strength. Increases in glycerol concentration reduced tensile strength and Young's modulus and increased percentage elongation to the breaking point so that films containing glycerol at $0.30 \mathrm{~g} / \mathrm{g}$ gelatin had the 
maximum percentage elongation to the breaking point $(\mathrm{p}<0.05)$. These results agree with those reported by Kilburn et al. [13]. Plasticizers come between polymer chains, weaken bonds between polymer molecules, increase the free space between molecules and, finally, cause motility of molecular chains, increase flexibility, and reduce tensile strength [14].

\subsection{Water Vapor Permeability}

Table 2 shows the effects of glycerol and sorbitol on water vapor permeability of gelatin films. All samples of gelatin films containing clay nanoparticles but no plasticizers exhibited high water vapor permeability. This phenomenon could be due to the absence of lateral branches and the presence of empty spaces in the structure of the films. Water vapor permeability is influenced by factors such as the hydrophilic or hydrophobic nature of the

Table 2. Results of measuring the water vapor flow rate.

\begin{tabular}{|c|c|c|c|c|}
\hline Type of film & $\begin{array}{l}\text { Thickness } \\
\text { (micrometer) }\end{array}$ & $\begin{array}{l}\text { Glycerol concentration } \\
\text { (gram per gram of gelatin) }\end{array}$ & $\begin{array}{l}\text { Sorbitol concentration } \\
\text { (gram per gram of gelatin) }\end{array}$ & $\begin{array}{c}\text { Water vapor permeability } \times 10 \\
\text { (gram/millimeter per } \\
\text { kilopascal/hour/square meter }\end{array}$ \\
\hline \multirow{12}{*}{$\begin{array}{l}\text { Bovine gelatin with } \\
\text { high Bloom values } \\
\text { containing clay } \\
\text { nanoparticles }\end{array}$} & 60 & 0.00 & 0.00 & $1.89 \mathrm{a}$ \\
\hline & 70 & 0.10 & 0.00 & $1.83 \mathrm{a}$ \\
\hline & 70 & 0.15 & 0.00 & $1.51 \mathrm{~b}$ \\
\hline & 70 & 0.20 & 0.00 & 1.28 \\
\hline & 60 & 0.25 & 0.00 & $1.30 \mathrm{c}$ \\
\hline & 70 & 0.30 & 0.00 & $1.78 \mathrm{a}$ \\
\hline & 60 & 0.00 & 0.00 & $1.89 \mathrm{a}$ \\
\hline & 70 & 0.00 & 0.10 & $1.40 \mathrm{~b}$ \\
\hline & 70 & 0.00 & 0.15 & $1.32 \mathrm{~b}$ \\
\hline & 70 & 0.00 & 0.20 & $0.86 \mathrm{c}$ \\
\hline & 70 & 0.00 & 0.25 & 0.65 c \\
\hline & 70 & 0.00 & 0.30 & 0.89 c \\
\hline \multirow{12}{*}{$\begin{array}{l}\text { Bovine gelatin with } \\
\text { low Bloom values } \\
\text { containing clay } \\
\text { nanoparticles }\end{array}$} & 50 & 0.00 & 0.00 & $1.42 \mathrm{a}$ \\
\hline & 50 & 0.15 & 0.00 & $1.22 \mathrm{~b}$ \\
\hline & 50 & 0.15 & 0.00 & $1.10 \mathrm{~b}$ \\
\hline & 50 & 0.20 & 0.00 & $1.05 \mathrm{~b}$ \\
\hline & 60 & 0.25 & 0.00 & $1.21 \mathrm{~b}$ \\
\hline & 60 & 0.30 & 0.00 & $1.70 \mathrm{a}$ \\
\hline & 50 & 0.00 & 0.00 & $1.42 \mathrm{a}$ \\
\hline & 50 & 0.00 & 0.10 & $1.03 \mathrm{~b}$ \\
\hline & 50 & 0.00 & 0.15 & $1.00 \mathrm{~b}$ \\
\hline & 50 & 0.00 & 0.20 & 0.45 c \\
\hline & 60 & 0.00 & 0.25 & $0.41 \mathrm{c}$ \\
\hline & 50 & 0.00 & 0.30 & $0.34 \mathrm{c}$ \\
\hline \multirow{12}{*}{$\begin{array}{l}\text { Fish skin gelatin } \\
\text { containing clay } \\
\text { nanoparticles }\end{array}$} & 60 & 0.00 & 0.00 & $1.86 \mathrm{a}$ \\
\hline & 50 & 0.10 & 0.00 & $0.76 \mathrm{c}$ \\
\hline & 70 & 0.15 & 0.00 & $0.52 \mathrm{~d}$ \\
\hline & 70 & 0.20 & 0.00 & $0.85 \mathrm{c}$ \\
\hline & 70 & 0.25 & 0.00 & $1.32 \mathrm{~b}$ \\
\hline & 70 & 0.30 & 0.00 & $1.29 b$ \\
\hline & 60 & 0.00 & 0.00 & $1.86 \mathrm{a}$ \\
\hline & 60 & 0.00 & 0.10 & $0.92 \mathrm{~b}$ \\
\hline & 60 & 0.00 & 0.15 & 0.57 c \\
\hline & 70 & 0.00 & 0.20 & 0.62 c \\
\hline & 70 & 0.00 & 0.25 & $0.12 \mathrm{~d}$ \\
\hline & 70 & 0.00 & 0.30 & $0.20 \mathrm{~d}$ \\
\hline
\end{tabular}

Different letters in each section suggest the averages of the studied property in each of the related tests were significantly different (p $<0.05$ ). 
material, and the presence or absence of cracks and fissures in the structure of the material and in its three-dimensional structure [15]. Sorbitol is a powder with six carbon atoms in its molecular structure, but glycerol is a liquid with three carbon atoms in each molecule. Adding these plasticizers to all of the samples reduced their water vapor permeability, which could be due to the close proximity of the lateral branches at low plasticizer concentrations. However, when glycerol concentration was raised to over $20 \%$ by weight and sorbitol to over $25 \%$ by weight, water vapor permeability improved due to increased fluidity, and probably because of increased spaces between the lateral branches resulting from the improved fluidity. Comparison of films containing plasticizers revealed that those with glycerol had the maximum and those with sorbitol the minimum water vapor permeability, probably because glycerol is more hydrophilic than sorbitol. The minimum water vapor permeability was observed in the fish-skin gelatin containing clay nanoparticles and sorbitol at $25 \%$ by weight.

Table 3 shows the measured rates of water vapor flow, which were higher in gelatin films containing clay nanoparticles that had glycerol compared to those that included sorbitol instead of glycerol $(\mathrm{p}<0.05)$. Films containing low concentrations of glycerol were brittle but their flexibility improved and their water vapor permeability increased when glycerol concentration was raised to over $20 \%$. In films without plasticizers, the brittleness and lower flexibility of the films, the joining together of the branches in gelatin structure, and the creation of empty spaces caused the formation of pores (microscopic break) facilitating water vapor permeability. Therefore, it seems water vapor passes from the spots where the capillary layers are broken and not through pores on the surface of the films, while the reverse happens in films containing plasticizers.

Permeability is influenced by the hydrophilic or hydrophobic nature of the material, the presence of cracks and fissures, spatial inhibition, and the structure of the films [15]. The effects of glycerol on the mechanical properties and inhibition of water vapor by protein films were studied by Hochstetter et al. [16], Lee et al. [17], and Hernandez et al. [18]. These researchers stated that increasing the concentration of glycerol improved water vapor permeability and absence of plasticizers in films was the cause of their brittleness.

Table 3. Results of water vapor flow rate.

\begin{tabular}{|c|c|c|c|c|c|}
\hline Film type & $\begin{array}{c}\text { Treatment } \\
\text { Glycerol: sorbitol }\end{array}$ & $\begin{array}{l}\text { Thickness } \\
\text { (micrometer) }\end{array}$ & $\begin{array}{c}\text { Glycerol } \\
\text { concentration (g/g gelatin) }\end{array}$ & $\begin{array}{l}\text { Sorbitol concentration } \\
\text { (g/g gelatin) }\end{array}$ & $\begin{array}{l}\text { Water vapor permeability } \\
\times 10\left(\mathrm{~g} / \mathrm{mm} / \mathrm{kPa} / \mathrm{h} / \mathrm{m}^{2}\right)\end{array}$ \\
\hline \multirow{8}{*}{$\begin{array}{l}\text { Bovine gelatin with } \\
\text { high Bloom values } \\
\text { containing clay } \\
\text { nanoparticles }\end{array}$} & $0: 0$ & 60 & 0.00 & 0.00 & $1.95 \mathrm{a}$ \\
\hline & $30: 0$ & 70 & 0.00 & 0.30 & 0,92 def \\
\hline & $25: 5$ & 70 & 0.05 & 0.25 & $0.63 \mathrm{f}$ \\
\hline & $20: 10$ & 70 & 0.10 & 0.20 & 0.75 ef \\
\hline & $15: 15$ & 70 & 0.15 & 0.15 & 1.14 cde \\
\hline & $20: 20$ & 70 & 0.20 & 0.10 & $1.22 \mathrm{~cd}$ \\
\hline & $5: 25$ & 70 & 0.25 & 0.05 & $1.51 \mathrm{bc}$ \\
\hline & $0: 30$ & 80 & 0.30 & 0.00 & $1.84 \mathrm{ab}$ \\
\hline \multirow{8}{*}{$\begin{array}{l}\text { Bovine gelatin with } \\
\text { low Bloom values } \\
\text { containing clay } \\
\text { nanoparticles }\end{array}$} & $0: 0$ & 60 & 0.00 & 0.00 & $1.21 \mathrm{ab}$ \\
\hline & $30: 0$ & 60 & 0.00 & 0.30 & $0.35 \mathrm{~d}$ \\
\hline & $25 ; 5$ & 70 & 0.05 & 0.25 & $0.64 \mathrm{~cd}$ \\
\hline & $20: 10$ & 70 & 0.10 & 0.20 & 0.79 bcd \\
\hline & $15: 15$ & 70 & 0.15 & 0.15 & 1.06 bc \\
\hline & $20: 20$ & 70 & 0.20 & 0.10 & $1.25 \mathrm{ab}$ \\
\hline & $5: 25$ & 70 & 0.25 & 0.05 & $1.61 \mathrm{a}$ \\
\hline & $0: 30$ & 80 & 0.30 & 0.00 & $1.68 \mathrm{a}$ \\
\hline \multirow{8}{*}{$\begin{array}{l}\text { Fish-skin gelatin } \\
\text { containing clay } \\
\text { nanoparticles }\end{array}$} & $0: 0$ & 80 & 0.00 & 0.00 & $1.86 \mathrm{a}$ \\
\hline & $30: 0$ & 70 & 0.00 & 0.30 & $0.21 \mathrm{f}$ \\
\hline & $25: 5$ & 60 & 0.05 & 0.25 & $0.54 \mathrm{e}$ \\
\hline & $20: 10$ & 70 & 0.10 & 0.20 & $0.81 \mathrm{~d}$ \\
\hline & $15: 15$ & 70 & 0.15 & 0.15 & $0.91 \mathrm{~d}$ \\
\hline & $20: 20$ & 70 & 0.20 & 0.10 & $1.31 \mathrm{~b}$ \\
\hline & $5: 25$ & 60 & 0.25 & 0.05 & $1.09 \mathrm{c}$ \\
\hline & $0: 30$ & 70 & 0.30 & 0.00 & 1.30 \\
\hline
\end{tabular}

Different letters in each section suggest the averages of the studied property in each of the tests were significantly different $(\mathrm{p}<0.05)$. 
In our research, the minimum water vapor permeability was that of the fish-skin gelatin film containing clay nanoparticles and sorbitol at $0.30 \mathrm{~g} / \mathrm{g}$ gelatin, and the maximum that of the bovine gelatin films with high Bloom values containing clay nanoparticles but no plasticizers $(\mathrm{p}<0.05)$.

\subsection{Color and Turbidity}

Using a box under controlled conditions (light, position of the camera, distance between the camera and the sample, camera angle, the sample and the light source) for taking images, and employing Photoshop software, the $\mathrm{L}^{*}, \mathrm{a}^{*}$, and $\mathrm{b}^{*}$ parameters were evaluated. Results indicated light intensity increased in bovine gelatin films with high Bloom values when sorbitol concentration was raised compared to glycerol, while in bovine gelatin films with low Bloom values and containing clay nanoparticles, and in fish-skin gelatin films with clay nanoparticles, light intensity declined. No significant differences were observed in the colors of the treatments $(\mathrm{p}<$ $0.05)$.

\subsection{Glass Transition Temperature}

Two heat absorption phenomena were observed in all of the samples. First, the amorphous portion of gelatin, that is in the glass state at ambient temperature [6] [19] [20], changed from the glass to the plastic state (that was observed as a step change in the specific heat). Following that, a heat absorption peak related to the melting of the crystalline portion was observed. These results suggest gelatin has a semi-crystalline structure. Marshall et al. [19], Pinhouse et al. [20] and Sobral et al. [6] previously reported similar results. In the region of glass transition, a minor heat absorption phenomenon was observed resulting from the thermal history of the polymer and the physical scheduling phenomenon, and was thoroughly studied in gelatin [21] [22]. Table 4 presents glass transition temperatures and melting temperatures of the three gelatin films containing clay nanoparticles. The glass transition test of bovine gelatin with high and low Bloom values containing clay nanoparticles have been investigated herein.

Fish-skin gelatin films containing clay nanoparticles with sorbitol at $0.25 \mathrm{~g} / \mathrm{g}$ gelatin together with glycerol at $0.05 \mathrm{~g} / \mathrm{g}$ gelatin had the highest glass transition temperature, and bovine gelatin films with low Bloom values containing clay nanoparticles and sorbitol at $0.25 \mathrm{~g} / \mathrm{g}$ gelatin together with glycerol at $0.05 \mathrm{~g} / \mathrm{g}$ gelatin had the maximum melting temperature. This shows the role played by sorbitol in increasing melting temperature and glass transition temperature, probably because sorbitol fills the empty spaces in gelatin structure and increases film stability, which leads to reduced water vapor permeability resulting from increases in sorbitol concentration.

\subsection{Film Structure}

Differences in the morphology of gelatin films containing clay nanoparticles were studied by taking images using a scanning electron microscope. As shown in Figure 6, three different morphologic types were observed among the samples. In films without plasticizers, the surfaces were uniform at $1000 \times$ magnification, which showed the uniformity and homogeneity of structure in these films (Figure 6). Of course, this was observed in all of the samples but, in samples containing glycerol at concentrations over $0.20 \mathrm{~g} / \mathrm{g}$ gelatin, glycerol increased fluidity between the lateral branches in the structure of gelatin. This created empty spaces between gelatin branches leading to higher percentages of elongation to the breaking point and to higher water vapor permeability in gelatin films containing clay nanoparticles. In samples that contained sorbitol at concentrations over 0.20

Table 4. Results of the glass transition test.

\begin{tabular}{lcc}
\hline Film type & $\begin{array}{c}\text { Treatment } \\
\text { (Glycerol: sorbitol) }\end{array}$ & $\begin{array}{c}\text { Glass transfer } \\
\text { temperature }\left({ }^{\circ} \mathrm{C}\right)\end{array}$ \\
\hline Bovine gelatin with high Bloom values containing clay nanoparticles & $25: 5$ & $\begin{array}{c}\text { Melting point } \\
\left({ }^{\circ} \mathrm{C}\right)\end{array}$ \\
Bovine gelatin with high Bloom values containing clay nanoparticles & $5: 25$ & 64.00 \\
Bovine gelatin with low Bloom values containing clay nanoparticles & $25: 5$ & 46.50 \\
Bovine gelatin with low Bloom values containing clay nanoparticles & $5: 25$ & 54.33 \\
Fish-skin gelatin containing clay nanoparticles & $25: 5$ & 46.33 \\
Fish-skin gelatin containing clay nanoparticles & $5: 25$ & 74.66 \\
\hline
\end{tabular}



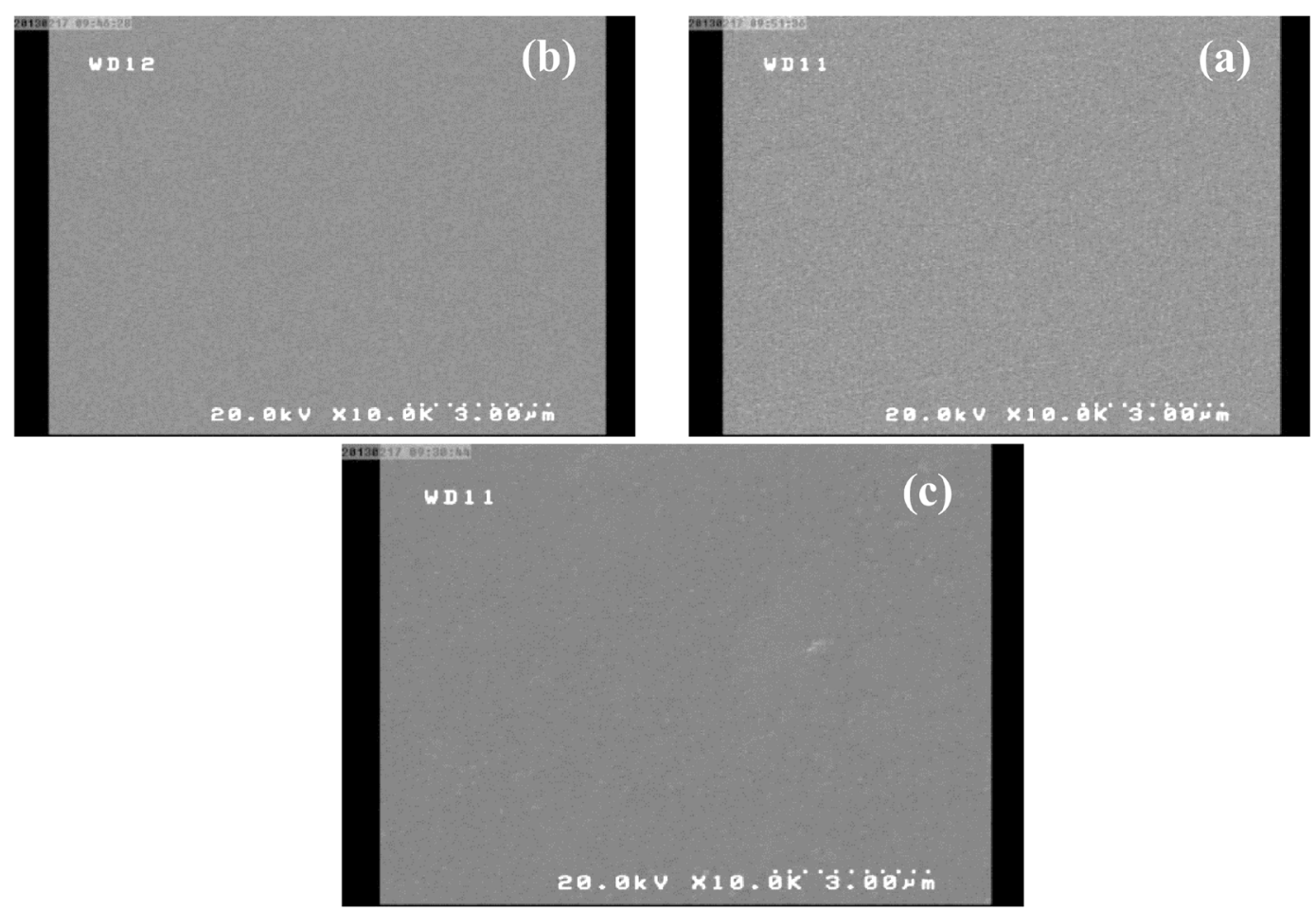

Figure 6. Images taken with the scanning electron microscope at 10000× magnification: (a) bovine gelatin with high Bloom containing clay nanoparticles; (b) Bovine gelatin with low Bloom containing clay nanoparticles; (c) Fish-skin gelatin containing clay nanoparticles.

g/g gelatin, sorbitol crystals positioned themselves in the empty spaces between gelatin branches, which led to greater strength and reduced water vapor permeability in the samples, particularly in films produced from fish skin (Figure 7).

\subsection{Heat Sealing}

Table 5 lists results of the heat sealing test of the samples. Based on the tensile strength test of the spot the gelatin films containing clay nanoparticles were heat sealed together in this research, all of the samples could be heat sealed. Among the heat sealed films, fish-skin gelatin films containing clay nanoparticles and glycerol at 0.30 $\mathrm{g} / \mathrm{g}$ gelatin had the maximum percentage of elongation to the breaking point (107.48\%) and also the highest tensile strength $(24.88$ megapascal) $(\mathrm{p}<0.05)$. Moreover, among the treatments optimized by a combination of the two plasticizers, fish-skin gelatin films containing clay nanoparticles and glycerol at $25 \%$ and sorbitol at $5 \%$ had the maximum elasticity and tensile strength. The heat-sealed films did not separate from each other at spots they were heat-sealed but were torn at other places (which showed the high heat sealability of these films). This phenomenon may be caused the melting of the gelatin structure due to heating and the re-entwining resulting from the applied heat. Moreover, based on results of the differential scanning calorimetry analysis, the mentioned samples melted at relatively lower temperatures compared to the other samples.

\section{Conclusion}

Gelatin films containing clay nanoparticles are brittle by nature, large quantities of water vapor pass through them, and they have low glass transition temperatures and low melting points. Glycerol alone improves the mechanical properties of gelatin films containing clay nanoparticles, and sorbitol improves water vapor permeability of these films. The mutual effects of these two plasticizers result in films with suitable mechanical properties, water vapor permeability and glass transition temperature, and raise their melting points. Fish-skin gelatin films containing clay nanoparticles and sorbitol at $25 \%$ and glycerol at $5 \%$ exhibited the best properties because of their low water vapor permeability, suitable mechanical properties, appropriate color, heat-sealing capability, 

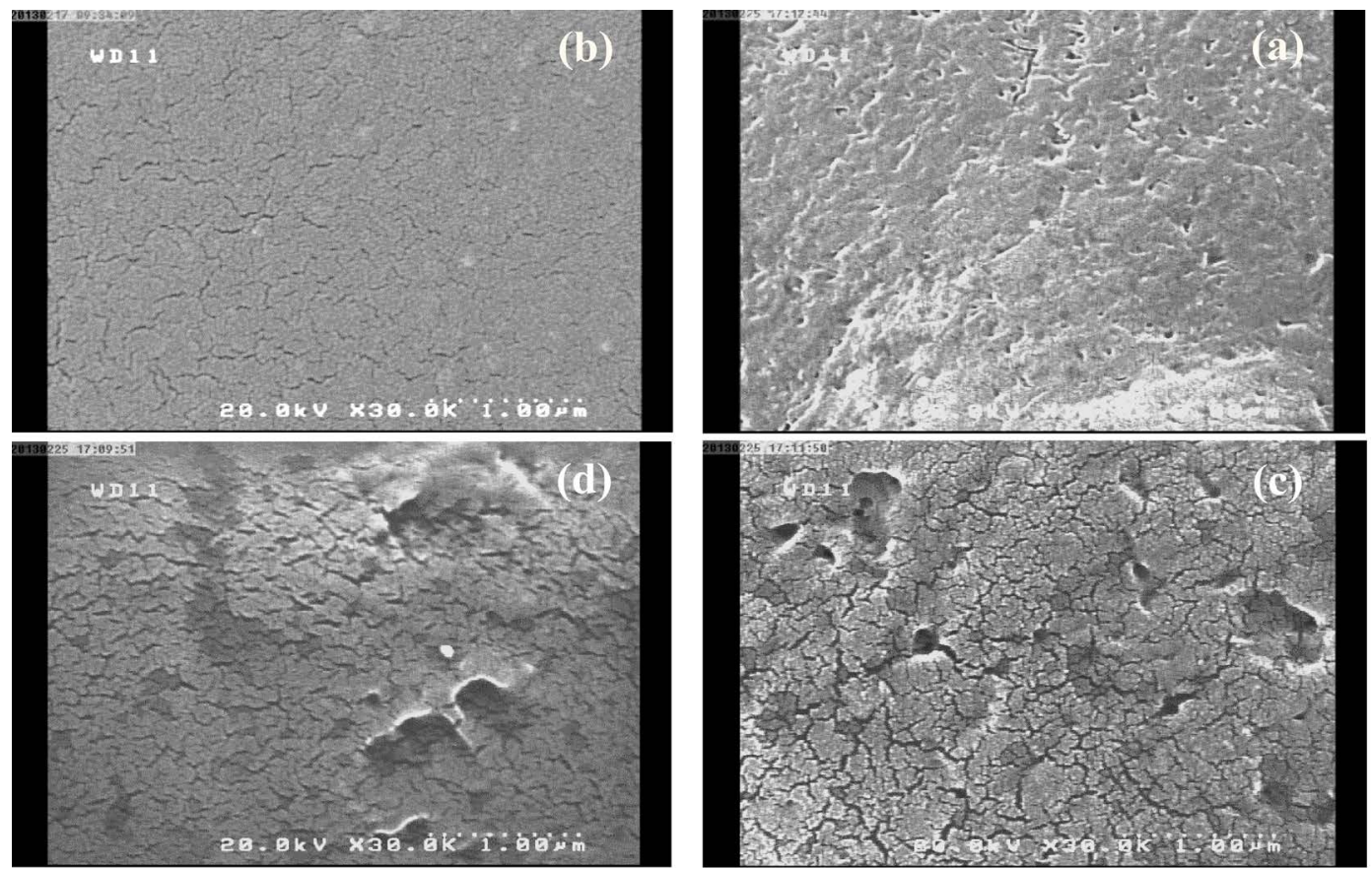

Figure 7. Images taken with an electron microscope: (a) The treatment of glycerol:sorbitol (25:5) on bovine gelatin with high Bloom containing clay nanoparticles at 10,000× magnification; (b) the treatment of glycerol:sorbitol (25:5) on fish-skin gelatin containing clay nanoparticles at 30,000× magnification; (c) the treatment glycerol:sorbitol (25:5) on bovine gelatin with high Bloom containing clay nanoparticles at 30,000× magnification; (d) the treatment glycerol:sorbitol (5:25) on bovine gelatin with low Bloom containing clay nanoparticles at $3000 \times$ magnification.

Table 5. Results of the heat-sealing test.

\begin{tabular}{|c|c|c|c|c|}
\hline Film type & $\begin{array}{c}\text { Treatment } \\
\text { Glycerol:sorbitol }\end{array}$ & $\begin{array}{l}\text { Thickness of the heat-sealing } \\
\text { spot (micrometer) }\end{array}$ & $\begin{array}{c}\text { Elongation to the breaking } \\
\text { point (percentage) }\end{array}$ & $\begin{array}{l}\text { Tensile strength of the } \\
\text { heat-sealing spot (megapascal) }\end{array}$ \\
\hline \multirow{8}{*}{$\begin{array}{c}\text { Bovine gelatin } \\
\text { with high Bloom } \\
\text { values containing } \\
\text { clay nanoparticles }\end{array}$} & $0: 0$ & 60 & $1.96 \mathrm{c}$ & $19.13 \mathrm{a}$ \\
\hline & $30: 0$ & 80 & 6.45 bc & $14.97 \mathrm{ab}$ \\
\hline & $25: 5$ & 60 & 13.55 bc & $15.47 \mathrm{ab}$ \\
\hline & $20: 10$ & 70 & $26.66 \mathrm{~b}$ & $13.79 \mathrm{ab}$ \\
\hline & $15: 15$ & 70 & 19.05 bc & $12.29 \mathrm{ab}$ \\
\hline & $20: 20$ & 70 & $57.87 \mathrm{a}$ & $10.69 \mathrm{bc}$ \\
\hline & $5: 25$ & 60 & $26.63 \mathrm{~b}$ & 9.84 bc \\
\hline & $0: 30$ & 80 & $27.98 \mathrm{~b}$ & $6.44 \mathrm{c}$ \\
\hline \multirow{8}{*}{$\begin{array}{c}\text { Bovine gelatin } \\
\text { with low Bloom } \\
\text { values containing } \\
\text { clay nanoparticles }\end{array}$} & $0: 0$ & 60 & $0.98 \mathrm{~d}$ & $9.35 \mathrm{abc}$ \\
\hline & $30: 0$ & 60 & $4.51 \mathrm{~cd}$ & $13.40 \mathrm{a}$ \\
\hline & $25: 5$ & 60 & $5.00 \mathrm{~cd}$ & $13.20 \mathrm{a}$ \\
\hline & $20: 10$ & 70 & 7.06 bcd & $9.21 \mathrm{abc}$ \\
\hline & $15: 15$ & 70 & 10.32 bcd & $11.56 \mathrm{ab}$ \\
\hline & $20: 20$ & 70 & $26.10 \mathrm{a}$ & 8.72 bc \\
\hline & $5: 25$ & 70 & $16.20 \mathrm{abc}$ & $3.42 \mathrm{~d}$ \\
\hline & $0: 30$ & 60 & $19.81 \mathrm{ab}$ & $5.58 \mathrm{~cd}$ \\
\hline \multirow{8}{*}{$\begin{array}{c}\text { Fish-skin gelatin } \\
\text { with clay } \\
\text { nanoparticles }\end{array}$} & $0: 0$ & 60 & $1.91 \mathrm{c}$ & 15.94 bc \\
\hline & $30: 0$ & 70 & $11.97 \mathrm{c}$ & $9.56 \mathrm{bc}$ \\
\hline & $25: 5$ & 70 & $16.35 \mathrm{c}$ & 8.52 c \\
\hline & $20: 10$ & 60 & $22.09 \mathrm{c}$ & 14.66 bc \\
\hline & $15: 15$ & 60 & $25.70 \mathrm{c}$ & 11.71 bc \\
\hline & $20: 20$ & 60 & $55.75 b$ & $17.29 \mathrm{~b}$ \\
\hline & $5: 25$ & 60 & $64.29 \mathrm{~b}$ & $17.23 \mathrm{~b}$ \\
\hline & $0: 30$ & 60 & $107.48 \mathrm{a}$ & $24.88 \mathrm{a}$ \\
\hline
\end{tabular}

Different letters in each section suggest the averages of the studied property in each of the tests were significantly different (p $<0.05)$. 
and high strength at the heat-sealed spots. Morphological study showed that films without plasticizers had uniform surfaces, but that samples containing glycerol at concentrations of over $0.20 \mathrm{~g} / \mathrm{g}$ gelatin exhibited cavities between gelatin chains, and that water vapor permeability in gelatin films containing clay nanoparticles. The results herein proved that the effect of plasticizers on mechanical properties and water vapor permeability of gelatin-based edible films containing clay nanoparticles is obvious and deserves further study.

\section{References}

[1] Liu, Z., Ge, X., Lu, Y., Dong, S., Zhao, Y. and Zeng, M. (2012) Effects of Chitosan Molecular Weight and Degree of Deacetylation on the Properties of Gelatine-Based Films. Food Hydrocolloids, 26, 311-317. http://dx.doi.org/10.1016/j.foodhyd.2011.06.008

[2] Motamedzadegan, A., Davarniam, B., Asadi, G., Abedian, A. and Ovissipour, M. (2011) Optimization of Enzymatic hydrolysis of Yellowfin Tuna Thunnus albacares Viscera Using Neutrase. International Aquatic Research, 2, 173-181.

[3] Shahiri Tabarestani, H., Sedaghat, N., Jahanshahi, M., Motamedzadegan, A. and Mohebbi, M. (2015) Physicochemical and Rheological Properties of White-Cheek Shark (Carcharhinus dussumieri) Skin Gelatin. International Journal of Food Properties. http://dx.doi.org/10.1080/10942912.2015.1050595

[4] Motamedzadegan, A., Ebdali, S. and Regenstein, J.M. (2013) Gelatin: Production, Applications and Health Implications, Halal and Kosher Regulations and Gelatin Production. Chap. 12, Nova Publishers.

[5] Kanmani, P. and Rhim, J.W. (2014) Physicochemical Properties of Gelatin/Silver Nanoparticle Antimicrobial Composite Films. Food Chemistry, 148, 162-169. http://dx.doi.org/10.1016/j.foodchem.2013.10.047

[6] Sobral, P.D.A., Menegalli, F., Hubinger, M. and Roques, M. (2001) Mechanical, Water Vapor Barrier and Thermal Properties of Gelatin Based Edible Films. Food Hydrocolloids, 15, 423-432.

http://dx.doi.org/10.1016/S0268-005X(01)00061-3

[7] Cao, N., Yang, X. and Fu, Y. (2009) Effects of Various Plasticizers on Mechanical and Water Vapor Barrier Properties of Gelatin Films. Food Hydrocolloids, 23, 729-735. http://dx.doi.org/10.1016/j.foodhyd.2008.07.017

[8] Rivero, S., García, M. and Pinotti, A. (2010) Correlations between Structural, Barrier, Thermal and Mechanical Properties of Plasticized Gelatin Films. Innovative Food Science \& Emerging Technologies, 11, 369-375. http://dx.doi.org/10.1016/j.ifset.2009.07.005

[9] Gontard, N., Duchez, C., Cuq, J.L. and Guilbert, S. (1994) Edible Composite Films of Wheat Gluten and Lipids: Water Vapour Permeability and Other Physical Properties. International Journal of Food Science \& Technology, 29, 39-50. http://dx.doi.org/10.1111/j.1365-2621.1994.tb02045.x

[10] Benzie, I.F. and Strain, J. (1996) The Ferric Reducing Ability of Plasma (FRAP) as a Measure of “Antioxidant Power”: the FRAP Assay. Analytical biochemistry, 239, 70-76. http://dx.doi.org/10.1006/abio.1996.0292

[11] Ghasemlou, M., Khodaiyan, F. and Oromiehie, A. (2011) Physical, Mechanical, Barrier, and Thermal Properties of Polyol-Plasticized Biodegradable Edible Film Made from Kefiran. Carbohydrate Polymers, 84, 477-483. http://dx.doi.org/10.1016/j.carbpol.2010.12.010

[12] Osés, J., Fernández-Pan, I., Mendoza, M. and Maté, J.I. (2009) Stability of the Mechanical Properties of Edible Films Based on Whey Protein Isolate during Storage at Different Relative Humidity. Food Hydrocolloids, 23, 125-131. http://dx.doi.org/10.1016/j.foodhyd.2007.12.003

[13] Kilburn, D., Claude, J., Schweizer, T., Alam, A. and Ubbink, J. (2005) Carbohydrate Polymers in Amorphous States: An Integrated Thermodynamic and Nanostructural Investigation. Biomacromolecules, 6, 864-879. http://dx.doi.org/10.1021/bm049355r

[14] Sousa, A.M., Sereno, A.M., Hilliou, L. and Gonçalves, M.P. (2010) Biodegradable Agar Extracted from Gracilaria Vermiculophylla: Film Properties and Application to Edible Coating. Materials Science Forum, 636-637, 739-744. http://dx.doi.org/10.4028/www.scientific.net/MSF.636-637.739

[15] Wang, Q. and Padua, G.W. (2005) Properties of Zein Films Coated with Drying Oils. Journal of Agricultural and Food Chemistry, 53, 3444-3448. http://dx.doi.org/10.1021/jf047994n

[16] Hochstetter, A., Talja, R.A., Helén, H.J., Hyvönen, L. and Jouppila, K. (2006) Properties of Gluten-Based Sheet Produced by Twin-Screw Extruder. LWT-Food Science and Technology, 39, 893-901. http://dx.doi.org/10.1016/j.lwt.2005.06.013

[17] Lee, S., Lee, M. and Song, K. (2005) Effect of Gamma-Irradiation on the Physicochemical Properties of Gluten Films. Food Chemistry, 92, 621-625. http://dx.doi.org/10.1016/j.foodchem.2004.08.023

[18] Hernández-Muñoz, P., López-Rubio, A., del-Valle, V., Almenar, E. and Gavara, R. (2004) Mechanical and Water Barrier Properties of Glutenin Films Influenced by Storage Time. Journal of Agricultural and Food Chemistry, 52, 79-83. http://dx.doi.org/10.1021/jf034763s 
[19] Marshall, A. and Petrie, S. (1980) Thermal Transitions in Gelatin and Aqueous Gelatin Solutions. Journal of Photographic Science, 28, 128-134.

[20] Pinhas, M.F., Blanshard, J., Derbyshire, W. and Mitchell, J. (1996) The Effect of Water on the Physicochemical and Mechanical Properties of Gelatin. Journal of Thermal Analysis, 47, 1499-1511. http://dx.doi.org/10.1007/BF01992842

[21] Badii, F., MacNaughtan, W. and Farhat, I. (2005) Enthalpy Relaxation of Gelatin in the Glassy State. International Journal of Biological Macromolecules, 36, 263-269. http://dx.doi.org/10.1016/j.ijbiomac.2005.06.008

[22] Badii, F., Martinet, C., Mitchell, J. and Farhat, I. (2006) Enthalpy and Mechanical Relaxation of Glassy Gelatin Films. Food Hydrocolloids, 20, 879-884. http://dx.doi.org/10.1016/j.foodhyd.2005.08.010 